\title{
Hypoxic incident in the operating theatre due to a central oxygen pipeline problem
}

\author{
*AA Abraham ${ }^{1}$ \\ Professor of Anaesthesiology ${ }^{l}$, YenepoyaUniversity, Mangalore, Karnataka
}

\section{Corresponding author:abraham3aby@gmail.com}

\begin{abstract}
Central oxygen pipeline failure is not a common problem. In our theatre complex compressed air got into the oxygen line while five surgeries were going on under general anaesthesia, causing hypoxia. The problem was identified in time and corrective measures were taken before any harm was done to the patients. The way in which this freak accident happened is described.
\end{abstract}

Keywords: central oxygen pipe line, hypoxia, oxygen failure, oxygen analyzer

\section{Case Report}

A 25 year old male patient was undergoing septoplasty under general endotracheal anaesthesia with $\mathrm{O}_{2}-\mathrm{N}_{2} \mathrm{O}$ mixture in 1:2 ratio, muscle relaxant and sevoflurane. The anaesthesia was uneventful from beginning till about 15 minutes into the surgery.

Then oxygen saturation slowly started falling to $90 \%$. The position of the tube in the trachea and proximal airway pressure was checked. The chest was auscultated for bilateral air entry and for any adventitious sounds. All were normal. Percentage of oxygen in fresh gas flow was increased to 50\% and sevoflurane was cut off. For a short time saturation improved, but again started to fall this time to $85 \%$. Some problem with the anaesthesia machine was thought of, and another machine was brought and connected to the patient. But the problem of falling saturation persisted. It was noticed that the same problem was occurring in the other theatres in the complex where general anaesthesia was administered. In total five surgeries were going on under general anaesthesia at that time.

So, we concluded that there was some problem in the central oxygen pipeline system. The pipe line hose was disconnected from the wall and emergency oxygen cylinders in the machines were turned on. The saturation became normal and all surgeries went on uneventfully. Later we came to know of the following facts. Service engineers were installing a pipeline system to a new theatre complex being built in the adjacent building, which passed through outer walls of the existing theatre. They had installed a common pipe line from the manifold room to our theatre. After giving $\mathrm{O}_{2}, \mathrm{~N}_{2} \mathrm{O}$, compressed air, and vacuum connections to our theatres, the line will continue to the new complex. The existing pipe line from the manifold to our theatre will be abandoned.

They were checking the new pipeline for leaks with compressed air, thinking that the connections to our theatre were closed. But the oxygen connection from the new pipe line to our theatre was open inadvertently and we were getting compressed air instead of oxygen. During the incident the pipeline alarm did not sound because there was no pressure fall within the system. It will not give a signal if an incorrect gas is present at normal pressure. Our machines are equipped with pressure sensor shut off valves in $\mathrm{N}_{2} \mathrm{O}$ line. They did not act and cutoff the $\mathrm{N}_{2} \mathrm{O}$ since the pressure in the oxygen line never fell, in fact it might have risen because of compressed air. Our machines do not have oxygen analysers nor oxygen failure alarms.

We were not informed of the work being done in the pipeline and our eternal vigilance had saved the patients from hypoxic catastrophe.

\section{Discussion}

The problems from central pipelines include cross connections, depletion of central gas supply, failure of alarms, pipeline leaks, debris in the pipeline and connection of wrong gas to manifold or wrong liquid reservoir. The most common 
reported causes are crossed connections either at the time of installation or during repair work.

A case of cross connection between $\mathrm{O}_{2}$ and $\mathrm{N}_{2} \mathrm{O}$ had been recently reported in a newly constructed theatre. The room had been used previously as a recovery room and converted to a theatre, where sequence of outlets of $\mathrm{O}_{2}$ and $\mathrm{N}_{2} \mathrm{O}$ was changed with suitable colour coding, but pipelines from manifold room were not connected to the corresponding changed outlets. ${ }^{1}$ It was very evident that cross connection tests were not carried out. In this incident precious time was lost in switching over to cylinder supply, resulting in permanent brain damage.

An incident of near miss had been reported from Australia, ${ }^{2}$ where a contractor was drilling through the floor of a major hospital when surgeries were going on in the theatre. He accidently broke the central oxygen pipeline. The oxygen leaked. Oxygen failure sounded. The supply was switched over to cylinder oxygen in time and no harm happened to the patients.

Oxygen pipe line should be ideally through the walls and if it has to cross roads or pavements, it should be marked and the construction workers be made aware of it.

Flooding of oxygen line with nitrogen had occurred in a hospital in USA, where nitrogen was used to test for leaks and shut off valve to that area did not prevent back flow. After this incident National Fire Protection Association of USA made it mandatory that whenever a new medical gas pipeline is connected to an existing system the source gas rather than nitrogen be used to test for leaks.

In another incident air was fed into the oxygen pipeline, ${ }^{3}$ in an ICU, because of a faulty air oxygen mixture value.

Intraoperative hypoxia had been reported from a hospital in USA because of erroneous filling of the liquid oxygen reservoir. 45 deaths resulted from 26 pipeline incidents in USA from 1972-1993. ${ }^{4}$ A substantially higher number of near misses also occurred during the same period, but catastrophes were prevented by prompt action taken. Many such incidents in our country go unreported, may be for fear of a bad name to the people involved or litigation that may follow. In an unreported case in a theatre in our city two children died of cardiac arrest from hypoxia, immediately after repair in the pipe line where a cross connection was made inadvertently between $\mathrm{O}_{2}$ and $\mathrm{N}_{2} \mathrm{O}$.

The hospital administration and service engineers who come for work in the pipe line should be educated about the seriousness of the catastrophes that can occur in the event of hypoxia. The theatre staff and technicians should also be sensitized about the matter.

All machines should have a standby cylinder and should be checked before starting each case. Every machine should be equipped with oxygen analyser and oxygen alarm. The cost of providing oxygen analyser and alarm in every machine is indeed big, but it should be weighed against advantages of safe anaesthesia, value of human life and huge compensation court may award in the event of any death or irreversible brain damage. In the primary and secondary level hospitals it is very difficult to have oxygen analyzers in every machine.

We are not very familiar with central pipeline system. It may take time to think about such a possibility if some problem occur and make adjustments. We should be aware of the whole pipeline installations and colour coding. Periodic checking of the pipeline and testing of alarms are advisable. Occasional emergency drills of pipeline supply failure will keep pipeline failure in our mind, if any hypoxic accidents occur in the theatre. Lack of communication between maintenance staff and clinical staff is a major issue, which should also be taken care of.

If pipeline failure is suspected, the wall hose should be disconnected immediately and the cylinder supply opened. If the hose is not disconnected, oxygen will flow back to the pipeline if the pressure is low there. And if the pressure in the pipeline is high like in our case, compressed air will flow to the machine causing hypoxia, since air is at a higher pressure of seven atmospheres than oxygen from the cylinder which is at a pressure of four atmospheres.

Our case highlights the following facts. Human error and negligence plays a very big role in 
causing life threatening accidents in the operating room. Oxygen failure safety devices bring a false sense of security to us. Inspired oxygen concentration monitoring is a must for safe practice of anaesthesia. No devices can replace the motto of eternal vigilance.

\section{References}

1. SP Devandan. Beware! Defects in pipelines can occur. Ind J Anaesth 2013; 57(4): 426-427.

2. J Weller, A Merry, G Warman. Anaesthetists' Management of $\mathrm{O} 2$ pipeline failure, Room for improvement. Anaesthesia2007; 62(2) : 122-126. http://dx.doi.org/10.1111/j.1365-044.2006.04899.x PMid:17223802

3. Thorpe JM, Railton R. Hypoxia due to air in oxygen pipeline, A case for oxygen monitoring in the theatre. Anaesthesia 1982; 37(6): 683-690.

http://dx.doi.org/10.1111/j.1365-

2044.1982.tb01283.x

4. Ehrenwerth J, Eisenkraft JB, Berry JM. Anaesthesia equipment: Principles and application -2nd edition, [chapter on internet] Elsevier 2012 [cited on July 2014]. Available at

http://www.inkling.com/read/2nd/chapter/hazardsof-medical-gas-delivery.

PMid:22445605 